\title{
VARIANT POSITION AND COURSE OF THE SUPERIOR CERVICAL CARDIAC BRANCH OF VAGUS NERVE
}

\section{Gabriel J. Mchonde *1,3, Tomoyuki Saino ${ }^{2}$.}

${ }^{* 1}$ Lecturer, Department of Cell Biology and Neuroanatomy, School of Medicine, Iwate Medical University, Iwate, Japan.

${ }^{2}$ Professor of Anatomy, Department of Cell Biology and Neuroanatomy, School of Medicine, Iwate Medical University, Iwate, Japan.

${ }^{3}$ Lecturer, Department of Anatomy and Histology, School of Medicine and Dentistry, University of Dodoma.

\section{ABSTRACT}

Variations on course and position of vagus nerve and its branches are extremely rare congenital anomaly. This manuscript presents a case of left superior cervical cardiac branch of the vagus nerve looping over the subclavian vein observed during routine dissection of a 72-yeays-old embalmed Caucasian female cadaver. In the same case, the left inferior cervical cardiac branch was taking origin from the superior cervical branch. Understanding the existence and developmental variations of these two cervical cardiac branches is of important in clinical presentations.

KEY WORDS: Vagus Nerve, Superior Cervical Cardiac Branch Of Vagus Nerve, Variations.

Address for Correspondence: Dr. Gabriel J. Mchonde, PhD, Lecturer, Department of Cell Biology and Neuroanatomy, School of Medicine, Iwate Medical University, Iwate, Japan.

Contact No.: +818062934529 E-Mail: gmchonde@yahoo.co.uk or mchonde@iwate-med.ac.jp

\section{Access this Article online}

Quick Response code Web site: International Journal of Anatomy and Research

ISSN 2321-4287

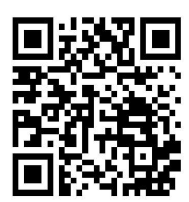

DOI: $10.16965 /$ ijar.2017.159 www.ijmhr.org/ijar.htm

Received: 24 Feb 2017

Peer Review: 24 Feb 2017

Revised: None
Accepted: 03 Apr 2017

Published (O): 30 Apr 2017

Published (P): 30 Apr 2017

\section{INTRODUCTION}

The vagus nerve (VN) is the tenth paired (left and right) cranial nerve carrying sensory fibers from the heart to the central nervous system and parasympathetic motor fibers to the heart. Usually, it has been described as most extensively cranial nerve, with roots arising from the medulla between the olivary nucleus and inferior cerebellar peduncle and extends through the jugular foramen into the carotid sheath between carotid artery and internal jugular vein to the cervical, thorax and abdominal regions [1-4]. On its way to the abdomen, several major branches arise to innervate various tissue organs, includes: meningeal, auricular, pharyngeal, laryngeal, cardiac, pulmonary, oesoph- ageal, and anterior and posterior vagal trunks branches. $[2,5,6]$.

Superior cervical cardiac branches of the vagus nerve (SCCVN) are described to arise in the neck just distal to the inferior vagal ganglion [7] and provide the parasympathetic innervation to the heart wall [8]. The left-SCCVN descends on the left side of the trachea anterolateral to the oesophagus and deep to the aortic arch to merge with the deep cardiac plexus [9]. We present a variant position and pathway of left-SCCVN on its way from the neck to the thorax. The knowledge on these anatomical variations is important for routine clinical procedures undertaken on the cervical and upper thoracic regions. 


\section{CASE REPORT}

A left-sided SCCVN with atypical position and pathway was observed during a routine undergraduate dissection of a 72-year-old preserved Caucasian female body with no previous history of surgical or heart condition (Fig. 1 and 2). The left vagus nerve gave a single superior cervical rami just distal to inferior vagal ganglion. The rami then descended together with the main VN trunk between the left common carotid artery and the internal jugular vein. At the level where the internal jugular vein united with the left subclavian vein, the left-SCCVN part away from the common pathway with the main VN trunk and move anterolateral, posterior to the distal quarter of the internal jugular vein. It then looped over the left subclavian vein at the junction between the internal jugular vein and left subclavian vein, at the level of thoracic inlet. Just after looping the subclavian vein, it gives a small inferior branch before continue to the aortic arch as the main superior branch. Small inferior branch deviates medially and downwards to reach the medial side of the aortic arch into the deep cardiac plexus, while the larger superior branch continues to terminate on the superficial cardiac plexus.

Fig. 1: Photograph from 72-years-old-embalmed female cadaver displaying the left lateral view of the cervical and the upper thoracic regions. Note the course and position of the superior cervical cardiac branch of the vagus nerve (black bold arrow) and the inferior cervical cardiac branch (white dotted arrow).

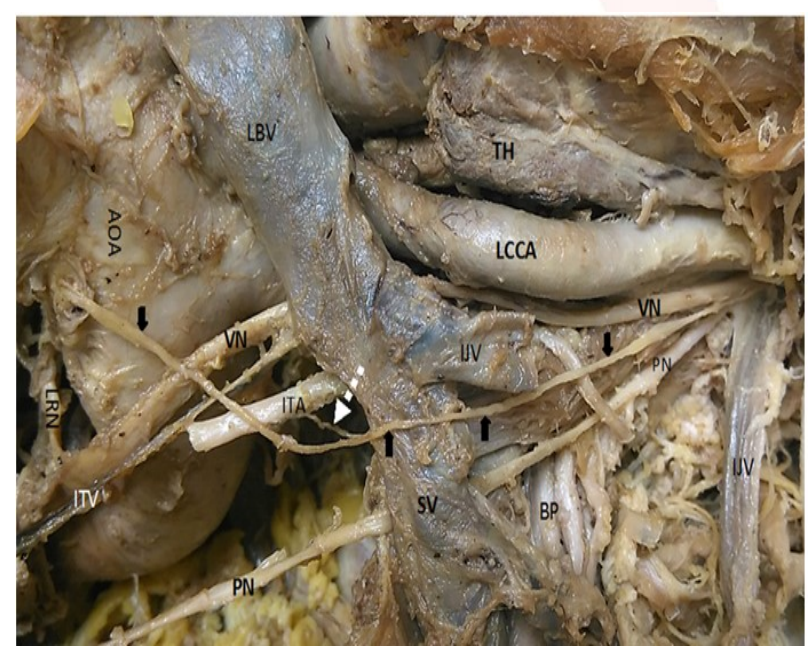

VN: vagus nerve, PN: phrenic nerve, IJV: internal jugular vein (cut), BP: brachial plexus roots, SV: subclavian vein, LCCA: left common carotid artery, TH: thyroid gland, LBV: left brachiocephalic vein, ITA: internal thoracic artery, AOA: aortic arch, LRN: left recurrent laryngeal nerve.
Fig. 2: Left side of the cervical region displaying the detail of the origin of the superior cervical cardiac branch of the vagus nerve (black bold arrow).

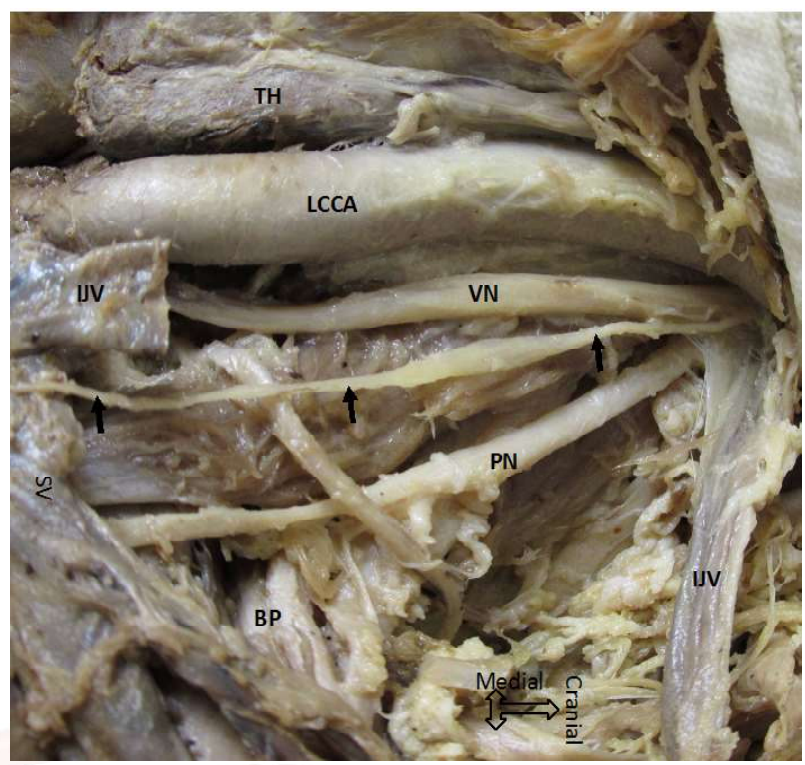

VN: vagus nerve, PN: phrenic nerve, BP: brachial plexus roots, SV: subclavian vein, IJV: internal jugular vein, LCCA: left common carotid artery, TH: thyroid gland.

\section{DISCUSSION}

The vagus nerve carries sensory and parasympathetic motor fibers from and to the heart respectively $[1,3,7]$, through its superior and inferior cervical cardiac branches via the cardiac plexus. In the observation reported in this article, left-SCCVN features like the division point, position, course and termination pattern seemed to be somehow different from the usual described anatomy of the cardiac plexus and associated vagal inputs.

The cardiac plexus is formed by branches from vagus and cervical sympathetic nerves, and anatomically divided into: ventral (superficial) located on the inferior surface of the aortic arch, and dorsal (deep) part located anterior to the left bronchus at the bifurcation of pulmonary trunk $[9,10]$.

The left vagus nerve usually gives $2-3$ superior and inferior cervical cardiac branches. The left superior branch usually described to descend anterior to oesophagus and deep to the aortic arch to merge with deep cardiac plexus, while the left inferior branch descends lateral to the trachea before passing over the arch of aorta to supply the superficial cardiac plexus $[9,10]$. However, this phenomenon was not observed in the current observation. In this the left vagus 
nerve gave a single common superior cervical branch that descends between the internal common carotid artery and the internal jugular vein to supply both the superficial and deep cardiac plexus.

The left inferior cervical cardiac branches of vagus nerve (ICCVN) usually are described to arise at the root of the neck just above the first rib $[3,6]$. However, in the current findings the left ICCVN arises from the left SCCVN just after passing over the left subclavian vein at the junction with the internal jugular vein. This phenomenon is remarkable and it is the first time being reported.

\section{EMBRYOLOGICAL NOTE AND CONCLUSION}

These neuronal variations can be explained through pharyngeal arches derivatives and associated neuronal growth cones behaviours during embryonic development. The vagus nerve gives branches that innervates derivatives from the fourth and sixth pairs of pharyngeal (branchial) arches $[11,12]$. Usually, the artery supplying the left fourth pharyngeal arch (left primitive aortic arch) persists and forms the definitive aortic arch, hence it remains associated with the vagus nerve branch. However, as the embryo grows, these arteries and nerves elongates and descend into their ultimate positions into the thorax [12] concurrent with their associated venous drainage.

Nerves elongates by actions of neuronal growth cones which are motile and actively explores potential target cells through intracellular signalling pathways via receptor regulated mechanisms $[13,14,15]$ resulting in the formation of postnatal neuronal connection.

Therefore, based on these embryological explanations, the present observation might be a result of faulty embryological activity of neuronal growth cones in the fourth left pharyngeal arch. On the looping over the left subclavian vein, it could be due to a delayed neuronal growth cone activity as a result the appropriate neuronal connection formed when venous drainage was already established since the venous system is not very uniform in development.

In conclusion, existence of anatomical variations involving the course and position of these two superior cervical branches of vagus nerve seems to be of important for medical literature in order to highlight unknown clinical presentations and the anatomical knowledge.

\section{ABBREVIATIONS}

VN - Vagus nerve

SCCVN - Superior cervical cardiac branch of vagus nerve

ICCVN - Inferior cervical cardiac branch of vagus nerve

\section{ACKNOWLEDGEMENTS}

We thank Prof. Yoh-ichi Satoh and Dr. Yan Jun for their moral and material support and all members in the Department of Anatomy, Iwate Medical University for their encouragement.

\section{Conflicts of Interests: None}

\section{REFERENCES}

[1]. Camara R and Griessenauer C. Anatomy of the vagus nerve. Nerve and nerve injuries. 2015;1: 385-397. Doi: 10.1016/B978-0-12-410390-0.00028-7.

[2]. Hermanowicz, N. Cranial nerves IX (glossopharyngeal) and X (vagus). In: Goetz, C. (Ed.), Textbook of clinical neurology, 3rd ed. Saunders Elsevier, Philadelphia, 1993;217-229.

[3]. Ellis, H. Clinical anatomy: A revision and applied anatomy for clinical students. Blackwell Science, Oxford, 2006.

[4]. Nolte, J., Sundsten, J. Cranial nerves and their nuclei. In: The human brain: An introduction to its functional anatomy, 6th ed. Mosby Elsevier, Philadelphia, 2009;295-322 (chapter 12).

[5]. Rucker, J.C. Cranial neuropathies. In: Daroff, R.B., Fenichel, G. M., Jankovic, J., Mazziotta, J.C. (Eds.), Bradley's neurology in clinical practice, 6th ed. Elsevier Saunders, Philadelphia, 2012;1745-1761.

[6]. Monkhouse, S. Cranial nerves: Functional anatomy. Cambridge University Press, Cambridge, 2006.

[7]. Hansen, J.T. Head and neck. In: Netter's clinical anatomy, 2nd ed. Saunders Elsevier, Philadelphia, 2010; 349-445.

[8]. Gilman, S., Manter, J.T., Gatz, A.J., Newman, S.W. Manter and Gatz's essentials of clinical neuroanatomy and neurophysiology. F. A. Davis, Philadelphia, 2003.

[9]. Wawrick R, Williams PL. Grays anatomy, $35^{\text {th }}$ ed. Longman. Norwich, 1973;1076.

[10]. Anderson JE. Grants atlas of anatomy, $8^{\text {th }} \mathrm{ed.}$ Igakushoin, Tokyo, 1984:1081-82.

[11]. Gelbert F, Assouline E, Hodes JE, Reizine D, Woimant $\mathrm{F}$, George $\mathrm{B}$, et al. MRI in spontaneous dissection of vertebral and carotid arteries. Neuroradiology 1991;33(2):111-113. 
[12]. Larsen, William J. Human embryology. New York: Churchill Livingstone, 1993;318-323

[13]. Landis SC. Neuronal growth cones. Ann Rev Physiol. 1983;45: 567-80.

[14]. Dent EW, Tang F, Kalil K. Axon guidance by growth cones and branches: common cytoskeletal and signalling mechanisms. Neuroscientist. 2003; 9(5):343353.
[15]. Mchonde GJ, Fabian FM, Nondoli GH. (2013). Bilateral multiple variations in the formation of the brachial plexus and its terminal nerves. A case report. Int J Anat Res, 2013;02:78-82.

How to cite this article:

Gabriel J. Mchonde, Tomoyuki Saino. VARIANT POSITION AND COURSE OF THE SUPERIOR CERVICAL CARDIAC BRANCH OF VAGUS NERVE. Int J Anat Res 2017;5(2.1):3731-3734. DOI: 10.16965/ijar.2017.159 